\title{
Caretaker-Adolescent Communication on Sexuality and Reproductive Health: My Perceptions Matter; A Qualitative Study on Adolescents' Perspectives in Unguja-Zanzibar
}

\author{
Saada A. Seif, Thecla W. Kohi \\ Department of Nursing Management, School of Nursing, Muhimbili University of Health and Allied Sciences, \\ Dar es Salaam, Tanzania \\ Email: salis1969@hotmail.com
}

Received 21 September 2014; revised 9 November 2014; accepted 26 November 2014

Copyright @ 2014 by authors and Scientific Research Publishing Inc. This work is licensed under the Creative Commons Attribution International License (CC BY). http://creativecommons.org/licenses/by/4.0/ (c) (i)

\section{Abstract}

This study was conducted to explore the perceptions of adolescents on caretaker-adolescent communication on sexuality. Using an Information-Motivation-Behavioural Skills model, this article highlights areas to emphasise when planning strategies to improve caretaker-adolescent communication on sexuality. Twelve focus group discussions were held with adolescents aged between 15 and 19 years, and data were analysed using content analysis. The participants found it important for caretakers to communicate with adolescents about sexuality to avoid sexual and related health risks. Caretakers were the most preferred communicators, by adolescents, on sexuality matters. It became apparent that information about the use of condoms was the most unpopular topic during the discussions, while information about the use of contraceptives seemed to be more interesting to the majority of the participants. From the adolescents' point of view, the barriers to communication about sexuality on the caretakers' side, include, the belief that such information might encourage promiscuity; some caretakers do not find it easy to discuss matters related to sexuality with their children; and others feel that some adolescents know more about sexuality than themselves. On the other hand, barriers on adolescents' side include, "fear" of the caretakers, some of whom seem harsh, unfriendly, and sometimes unapproachable. Following the findings, it is being suggested that intervention strategies that would help to alleviate communication barriers would consequently facilitate caretaker-adolescent discussions about sexuality and reproductive health. 


\section{Keywords}

\section{Adolescent/Youth, Caretaker/Parent, Communication, Sexuality, Reproductive Health}

\section{Introduction}

Studies [1] [2] have been conducted to examine factors which influence young people's sexual behaviours, and one of the factors identified as influencing such behaviours is parent-adolescent communication about sexuality. In this study, the words "caretaker" and "parent" are used interchangeably, likewise, the words "adolescent" and "youth". Communication about sexuality between parents or caretakers and their children has been identified as a protective factor for a range of sexual behaviours, including a delayed sexual debut [3]. Children who talk with their parents about sexual matters, or who get education on sexuality at home, are more likely to postpone sexual activity than those who do not access such education. Again, with this awareness, when these adolescents eventually become sexually active, they have fewer sexual partners and are more likely to use contraceptives and condoms than those who do not discuss sexual matters with their parents [4]; and consequently, they are at reduced risk from unintended pregnancies, abortion, Human Immunodeficiency Virus (HIV) infection, and other Sexually Transmitted Diseases (STDs).

Despite the evidence that communication about sexuality between caretakers and adolescents could greatly help to reduce the risky sexual behaviour of adolescents, discussions on sexuality have sometimes been considered to be culturally shameful [5] [6]; and it has been reported that there is concern that education on sexuality may contribute to early sexual experimentation among young people. However, such fears have not yet been supported by evidence.

The topic of caretaker-adolescent sexuality communication as described by adolescents is important because young people in Sub-Saharan Africa are reported to have risky sexual behaviours, with the following consequences: 1) unplanned pregnancies: it is reported that in Sub-Saharan Africa about 14 million unplanned pregnancies occur every year, with almost half occurring among women aged between 15 and 24 years [7]; and in Tanzania, a study done among youths showed that $27.1 \%$ of pregnancies were unplanned [8]; 2) Sexually Transmitted Infections (STIs): in Tanzania, about 2.2 million adults and children were estimated to have been infected with STIs. Approximately 17\% of children under the age of 15 years had been infected by STIs, and about $50 \%$ of the STIs occurred before the age of 29 years [9]; 3) Human Immunodeficiency Virus (HIV) and Acquired Immunodeficiency Syndrome (AIDS): about 42\% of new HIV infections occur in people aged 15 and older, with nearly 80\% living in Sub-Saharan Africa [10]. In Tanzania, HIV infection among girls aged between 15 and 19 in both rural and urban areas is $1.3 \%$, while it is $0.7 \%$ for young men of the same age group [11]; 4) abortion: it is reported that adolescents aged between 15 and 19 years are responsible for $25 \%$ of all the unsafe abortions carried out in Africa [12].

All these consequences have undesirable impact on the physical, psychological, economic and social wellbeing of the affected adolescents, considering that the future growth and success of the country depend on these young men and women. Although there is a decline in HIV incidences and reduction in new HIV infections among young people worldwide and especially in Sub-Saharan Africa [10], risky sexual behaviours among adolescents are still at an alarming rate.

\subsection{Adolescent's Risky Sexual Behaviours}

Early sexual debut: Early initiation into sexual activity prolongs the period of exposure to risk of contracting STIs, HIV, unplanned pregnancy, as well as unprotected intercourse and multiple partners [13] [14]. In many countries, the proportion of adolescents having premarital sex before the age of 18 has risen [15]. In Tanzania, it is shown that $13 \%$ of women would have had sex by the age of 15 years, and $59 \%$ by the age of 18 years [16]. This increase in sexual activity puts young people at a great risk of unplanned pregnancies as well as STIs including HIV/AIDS [17].

Multiple sexual partnerships: It has been reported that more than $40 \%$ of sexually experienced adolescent men in some countries, and as many as $10 \%$ of women may have had two or more sexual partners in the past year [18]. Moreover, young people were reported to have high rates of partner change: $74 \%$ of men and $39 \%$ of 
women aged $15 \pm 19$ were reported to have had more than one lifetime partner, and 34\% of the young men were reported to have had five or more partners [19]. Having multiple sexual partners puts adolescents at risk of contracting HIV and other sexual transmitted diseases.

Unprotected sexual intercourse: The use of condoms remains rare among married young people and moderate among unmarried sexually active young men and women. Moreover, its use is highly inconsistent according to the reports of sexually active adolescent men [20]. In Tanzania, condom use among females aged between 15 and 24 years old is slightly lower at $46 \%$, while for males it is at $49 \%$ [11].

\subsection{Young People's Perceptions on Caretaker-Adolescent Communication on Sexuality}

The task of educating teenagers about sexuality involves not only the sending of accurate information by parents but also the requiring receptivity on the part of the listener and mutual regulation of information flow, as understandings change [21]. Therefore, as much as caretaker-adolescent communication about sexual and reproductive health is important, it is also important how such communication is managed and perceived by the young persons, although probably not much about this topic may be known.

As far as young people are concerned, they admit that communication about sexuality between themselves and their parents is important as such communication helps the former to avoid sexual and related health risks, and most are willing to discuss sexual and reproductive health matters with their parents [21]. Those who are in school seem to be more forthcoming to discuss such matters with their parents, while those who are out of school are reported to be less willing to discuss with their parents issues related to sexual and reproductive health [22].

During the literature search, it was important to find out what kind of people the adolescents prefer to communicate with, on matters related to sexuality. It was found out that while most male adolescents, both in-school and out-of-school, prefer to talk to their friends, in-school and out-of-school females prefer to obtain this information from their mothers [23]. Other studies have also shown that between the two parents, the mother is the preferred party, when it comes to communication about sexuality for both male and female adolescents [24] [25]. This is quite an interesting observation, and it would be interesting to find out why.

In the young people's views, the appropriate age to start communicating about sexuality as explored by Guilamo-Ramos et al. (2012) is between ages 18 and 21, or after marriage [26]. However, a study done by Tesso et al. (2012) showed that more communication seems to occur from the ages of 15 to 16 years for females, and 17 to 18 years for males, and the proportions tend to decline at the age from 20 to 24 years [27]. It is also reported that only a small proportion (one-fifth of males and one-third of females) among younger people (10 to 14 years) were reported to have communicated with their parents [27].

Looking at research reports, the only study which has documented young people's views on what information should be communicated by parents was a study by Rosenthal and Feldman (1999), in which there was pervasive agreement among adolescents that parents should only communicate about sexual safety which includes safe sex, contraceptive use, STIs and HIV, and to a lesser extent development and societal concerns which includes biological aspects, pregnancy and abortion [21]. Moreover, topics regarding the choice of partner, the nature of activities engaged in, and the emotions and feelings involved in sexual activities, seem to be personal and therefore are outside what might seem appropriate for parents and their adolescent children to discuss [21]. However, Tesso et al. (2012) showed that a large proportion of adolescents were reported to have discussed with their caretakers associated risk aspects of sexual and reproductive health topics like unwanted pregnancy and HIV/AIDS, followed by discussion on preventive aspects like condom use and family planning, while a low proportion of both males and female were reported to have discussed with their parents biological aspects of sexual and reproductive health topics such as body change during puberty and menstruation [27].

Barriers affecting communication on sexuality between caretakers and adolescents were also explored. Fear of parents, embarrassment to discuss matters related to sex with parents, taboo attached to sex, parents' failure to put aside time to listen, and parents' lack of interest to discuss such matters, are among the factors identified by young people as negatively affecting discussion about sexual and reproductive health issues with their parents [27]. A study by Wamoyi et al. (2010) attributed lack of direct parent-child communication about sexuality to lack of parent-child closeness, shame, fear and cultural norms. As it was quoted in this study, one young person said that "only parents who truly love their children would chat with them” (primary school girls) [22].

There are several studies that have been conducted on parent-adolescent communication on sexuality but only few that have focused on parent-adolescent communication on sexuality (as described by adolescents) have been 
documented [21] [22] [27]. There is inadequate information about adolescents' views, needs and attitude to receiving information from their caretakers. Therefore, the aim of this study, as already pointed out, was to explore the perceptions of adolescents on caretaker-adolescent communication on sexuality in the context of the importance of such communication, preferred communicator, most suitable age to start communicating about sexuality, type of information to be communicated, and barriers that might affect such communication. Knowledge of adolescents' perceptions about communication on sexuality with their caretakers will allow the attainment of a deeper understanding of adolescents' needs and attitude towards communication with their caretakers on matters relating to sexuality, which is necessary for the development of effective interventions.

\subsection{Theoretical Framework: Information-Motivation-Behavioural Skills (IMB) Model}

The Information-Motivation-Behavioural Skills (IMB) model was used in this study to highlight areas that need more attention when designing intervention aiming at improving parent-child communication on sexuality. The theory-based research is necessary to identify the determinants of such communication, which can be targeted in the context of a family-based intervention in Unguja.

This model explains behaviour development as a function of information, motivation and behavioural skills [28]. An important assumption of the IMB model is that unhealthy behaviour is often caused by deficits in health information, motivation, and behavioural skills; in fact, these deficits prevent the occurrence of health enhancing behaviours [29]. In this study, the "information construct" includes the contents of reproductive health and sexuality, and the perceived importance of communication on sexuality. The "motivation construct" includes: 1) perceived risk by adolescents to get reproductive health problems, 2) social norms, and 3) attitude towards communication about sexuality. "Behavioural skills construct" includes the perceived efficacy in communicating about sexuality.

\section{Methodology}

\subsection{Design}

An exploratory study design which used the qualitative approach was used to explore the perceptions of adolescents on caretaker-adolescent communication about communication.

\subsection{Setting}

The study was carried out between September and November 2013 in all the three regions of Unguja, which are Urban West, North, and South. Each region has two districts which were all involved in the study. These six districts include Urban, West, North A, North B, South, and Central. The national population and housing census in 2012 estimated that about 896,721 people resided in Unguja and about 406,848 in Pemba. These two sister islands make Zanzibar. Urban West Region has approximately 593,678 people, North Region has about 187,455 people and South Region has 115,588 people. The population of Zanzibar is very youthful in character, with $43.8 \%$ of its residents under 15 years, and 35\% between 15 and 35 years old. Moreover, the Tanzania Household Budget Surveys carried out in 2004/05 and 2009/10 show an increase in the number of adolescents from 265,037 in 2004/05 to 325,970 in 2009/10, with a remarkable increase in the number of adolescents residing in urban areas from 51,562 in 2004/05 to 141,343 in 2009/10 [16].

\subsection{Informants}

Purposive sampling was used to select adolescents, both male and female, from all the regions; and the selected sample participated in focus group discussions. A total of 30 males and 42 females with age ranging from 15 to 19 years participated in focus group discussions. The participants included adolescents who were still at school, those who had dropped out of school for several reasons including abscondment and pregnancy. The participants also involved those who were married, divorced, separated, widowed and cohabiting, and those who had experienced reproductive health problems like pregnancy. All participants were identified through their respective Sheha (community leader at the level of Shehia/street/village).

\subsection{Data Collection}

Twelve Focus Group Discussions (FGDs) were conducted; and of these FGDs, six were conducted with male 
participants and six with female participants. The focus group discussions for males were facilitated by trained same gender moderators and note-takers, while the focus group discussions for females were facilitated by the principal investigator and trained female note-takers. An average of eight participants took part in each discussion, lasting for about one and half to two hours. The discussions were held in Kiswahili which is spoken by all participants, and they were also audio-recorded. All FGDs were held in schools during weekends, when the classrooms were free. Permission for adolescents to participate in this study was obtained from their caretakers, and written assent was obtained from the adolescents themselves.

\subsection{Data Analysis}

All interviews were transcribed and translated into English and were analysed by using content analysis approach. The interviews were read several times to understand implications and contexts. This was followed by extraction of meaning units from the transcripts. The meaning units were condensed by shortening the original text while maintaining the central meaning. The condensed versions were later assigned codes, which were grouped into similar categories (Table 1). The Principal Investigator (PI) always cross-referenced between Kiswahili and English transcripts to ensure that the meaning units, codes and categories of the two languages were congruous. This analysis used already designed coding schemes (anticipated codes/priori codes) which had been developed from the question guide. After the coding process had been completed, searches were carried out which involved thoroughly reading the individual codes for emerging patterns. The table below shows the priori codes and categories from the focus group discussions involving adolescents, both male and female.

\subsection{Ethical Consideration}

This study was approved by Muhimbili University of Health and Allied Sciences (MUHAS) Research Ethical Committee, after, the permission to conduct the study had been sought from Zanzibar Research Committee and from the Revolutionary Government of Zanzibar, through its Regional Officers to whom the objectives of the study were clearly explained. Each participating adolescent was asked to give written consent. For adolescents below 18 years of age, permission to participate was granted by their caretakers. It was made clear that any participant would be free to withdraw from the study, any time. It was also made clear that information obtained from the study would be treated with strict confidentiality, and would be used only for the intended research purposes. Participants were provided with PI contacts to report any cases of infringement upon their rights.

\section{Findings}

As already indicated in preceding sections, the main preoccupations of the study were to investigate perceptions by adolescents on a number of issues relating to how they communicate about sexuality: importance of communication on sexuality, people with whom they prefer to communicate about sexuality, appropriate age to start such communication, topics to be communicated, and barriers of effective communication. Therefore, all texts from interviews were analysed for identification of these parameters, and participants' own submissions are shown in italics, below.

\subsection{Characteristics of Informants}

The socio-demographic characteristics of adolescent participants who were interviewed about their perception on parent-child communication on sexuality are summarized in the Table 2.

\subsection{The Importance of Communication on Sexuality}

Generally, there was consensus among participants that it is very important for caretakers to communicate with adolescents about sexuality. It is believed that the reproductive health information given is adequate to make adolescents capable of protecting themselves from getting into reproductive health problems, through development of self-awareness, ability to make informed decisions, and ability to avoid sexual and health related risky behaviours. As one participant said, "The importance is obvious, because we young people usually do things blindly, but if we are made aware, then we will make informed decisions” (19-year-old, male adolescent).

Another participant emphasised the importance of providing sexuality and reproductive health information to adolescent; this one admitted thus: "As far as I am concerned, it is important to provide reproductive health in- 
Table 1. Adolescents’ perceptions on caretaker-adolescent communication on sexuality.

\begin{tabular}{|c|c|}
\hline Category: & Codes: \\
\hline \multirow[t]{4}{*}{ 1. Importance of sexuality communication } & -self awareness \\
\hline & -protect self from the effects of youth \\
\hline & -make informed decisions \\
\hline & -avoid risky behaviour \\
\hline \multirow[t]{3}{*}{ 2. Appropriate age to start communication on sexuality } & -before puberty \\
\hline & -at puberty \\
\hline & -after puberty \\
\hline \multirow[t]{2}{*}{ 3. Information to be communicated } & $\begin{array}{l}\text {-protective (aspect) of sexuality: (abstaining from sex, avoiding risky } \\
\text { behaviour, avoiding drugs, avoiding alcohol and tobacco use, wearing } \\
\text { respectful clothing, staying away from bad influence, resisting peer } \\
\text { pressure, learning about condom use and contraception, building life skills) }\end{array}$ \\
\hline & -associated risk (aspect) of sexuality: (STIs, HIV and teenage pregnancy) \\
\hline \multirow[t]{4}{*}{ 4. Preferred person to talk about sex } & -caretakers/parents \\
\hline & -school teacher \\
\hline & -doctor \\
\hline & -friends. \\
\hline \multirow[t]{12}{*}{ 5. Barriers of communication on matters related to sex } & -fear by parent/adolescent \\
\hline & -unhelpful norms \\
\hline & -unconstructive beliefs \\
\hline & -lack of RH knowledge \\
\hline & -too much love \\
\hline & -poor relationship \\
\hline & -lack of survival skills \\
\hline & -negative attitude \\
\hline & -adolescents do not listen \\
\hline & -lack of time to talk \\
\hline & -too young to be told \\
\hline & -living with a single parent \\
\hline
\end{tabular}

Table 2. The socio-demographic characteristics of adolescents participants.

\begin{tabular}{ccc}
\hline Characteristics & Male & Female \\
\hline Age 15 - 19 years & 30 & 42 \\
Married & 2 & 3 \\
Who are still at school & 19 & 30 \\
Who dropped out from school & 9 & 9 \\
Who experienced reproductive health problems & 0 & 6 \\
\hline
\end{tabular}

formation to adolescents, because once we get this information we will be able to protect ourselves from risky behaviours like sexual temptation... I will also be aware that should I engage in sexual intercourse, I may contract STIs, or HIV, or I may get pregnant...” (16-year-old school girl).

According to these participant' perceptions, it is important to provide sexuality and reproductive health information to adolescents because of the apparent sexual and health related risky behaviours, as may have been noticed among such adolescents. Such risky behaviours include: having multiple sexual partners, peer pressure, early sexual debut, taking advantage of globalisation, drugs and alcohol use, and excessive involvement in leisure: One participant said, “As far as I know, most adolescents nowadays like to engage in uncontrolled leisure 
activities, entertainment, music, alcohol, and sexual intercourse at a young age, and all this, it would seem, is due to lack of reproductive health knowledge" (18-year-old male adolescent).

Another participant added, “Amm (...) it is true that today's young ones display these behaviours; they like to engage in sex very often and with different people, and once we get 'that thing' (become pregnant) we go for abortion. For us youth, this kind of behaviour is uncalled for..." (17-year-old adolescent female).

There was also the following comment from a participant, who gave the following long narration:

Nowadays most young people have an obsession for what they think is "to move with the times"- that of being a "sharo". Teens are craving for stylish clothes, nice shoes, jewelry and stylish hair cut for men; and this "sharoness" has spoiled many boys, because everybody wants to wear these unusually expensive, designer clothes. Apart from such clothing being very expensive, the styles also come with a culture, most of which these young men and women are unfamiliar. This way, some of the youth start losing direction... (18-year-old adolescent female).

The most apparent risky behaviour, as noticed from the surroundings where the informants were living, is to engage in sexual activities at a young age. It was revealed by most participants that some youths were engaging themselves in sexual activities even before they reach the age of 15 years, and quite a good number do this with people who are much older than themselves. Giving testimony, one adolescent male said, “...for example, when some adolescents attain the age of 10 years, they start to engage in sexual activity; but they do not do this with their age mates. They would rather engage with a partner who is much older than themselves. Nine year olds are taking in partners, some of whom are twenty years old. This is ridiculous!” (18-year-old adolescent male).

\subsection{The Preferred Communicator on Sexuality Matters}

As said earlier, it was important to find out what kind of people adolescents prefer to communicate with, on matters of sexuality. It was revealed that the majority preferred parents or caretakers. Parents were chosen because of their primary role of preparing young people for adult life, and because most of them stay and live with their children under one roof. They therefore should be more familiar with the lives of their children than anybody else. Teachers were also mentioned by some of the participants as preferred communicators on sexuality matters because of their role of shaping the behaviour of their students, and because they also spend a lot of time with these adolescents. Only few chose doctors as people they would like to communicate with on sexuality matters; this group was chosen for the reason that doctors have a lot of knowledge on reproductive health. Finally, friends were mentioned because of the closeness and intimacy that exist between and among themselves. For those who prefer parents to communicate with them, one participant said, "...I think it should be parents, because they are the ones who live with you and thus they know more about your life than anyone else, and they can explain those things to you in a way that you would understand better than when told by anyone else" (18year-old school male adolescent).

Others thought that it would be best if adolescents communicated this information with friends; one of the respondents explained: “...yes friends, we normally understand one another as friends. One might ignore what he/she is told by his/her parents, but this same person might trust and listen to same advice coming from a friend" (17-year-old school male adolescent).

As far as the proper age to initiate communication about sexuality with adolescents was concerned, most respondents were of the opinion that adolescents should start being given this information once they reach puberty (between ages 9 to 15), because they claimed, this is the age in which adolescents start developing sexual and related health risky behaviours, and it is in this period when physiological changes (secondary sexual characteristics) become apparent. A good number suggested that this communication should start at an earlier age of between 5 to 7 years, because they said that when such information is given at an early age such as this, the children will start getting used to this kind of conversation. When they grow older, it is likely that they will no longer feel embarrassed when talking about sexual matters to older people. One respondent gave a Kiswahili saying-“samaki mkunje angali mbichi"; which could be translated as "strike the iron while still hot" (16-yearold school male adolescent).

This is a call to parents/caretakers to start talking to their young children, early enough, about issues related to sexuality and health.

Few participants thought that this information should be communicated after puberty, when these adolescents have attained the age of between 16 and 18 years; because at this age, the adolescents are nearly ready to get 
married and they are expected, by this time, to be aware of the kind of behaviour that would be considered risky. One of these female respondents said, "...I think the adolescent should be given this information once she reaches 18 years, because at this period she has quite a high level of self-awareness, and even if she decides to engage in sexual activity, she is capable of giving birth safely, at that age" (19-year-old, female adolescent).

In this research it was considered important to find out if the communication about sexuality between caretakers and adolescents should be on the same sex basis-whether male caretakers should handle male adolescents and female caretakers should deal with female adolescents. Another scenario would be whether a male or female caretaker should handle both male and female adolescents at the same time. The majority were of the opinion that communication about sexuality should not be based on sex because knowledge is usually delivered by the person who has it - whether male or female. Moreover, they opined, the child will understand and take information more seriously if the male and female caretakers will be seen to concur on matters of sexuality. A few participants seemed to disagree with any caretaker, talking about any topic, to any adolescent (male or female). These advised that a caretaker should communicate only on selective topics of sexuality when addressing adolescents of the opposite sex. One participant said, “...both parents have the responsibility of preparing young people for adult life but there are issues that a male caretaker should not share with his female adolescents, and vice versa..." (17-year-old, school female adolescent).

They elaborated that information that should not be communicated with the opposite sex was information involving mentioning the private parts and menstruation. One of them said, “...information which includes mentioning the private parts, or information about menstruation, should be left to female caretakers to handle; otherwise if such information is handled by male caretakers, there would be no respect" (19-year-old, school female adolescent). There was also the question of culture-that it would be considered unethical for a mother to talk to her son, or a father to his daughter, on issues about sex.

\subsection{Topics to Be Communicated}

It was important to find out what participants thought about the suitability of topics on sexuality and reproductive health, which caretakers should share with their adolescents. The majority suggested that caretakers should communicate with adolescents about the preventive aspects of sexuality, e.g. avoiding bad groups, abstaining from alcohol and drug use, refraining from unnecessary and unprotected sexual activity, avoiding imitating others especially people of other cultures, shunning any sexual temptations and wearing respectable clothing. Apart from this, many adolescents emphasised that caretakers should communicate about the associated risk aspects of sexuality like HIV, STIs, and teenage pregnancy. One was heard saying, "Things that adolescents should be told by their caretakers should be about the issue of imitating others, because we (young people) really like to imitate everything we see, and also about teenage pregnancy, and sexually transmitted diseases..." (15-year-old, school female adolescent).

Another participant went further to suggest that the information to be communicated to adolescents should be age specific; that is, those who are 15 years old should only be told about abstaining from sex, but for those who are above 15 years should be told about safer sex, assuming that at this age, most adolescents are sexually active compared to those who are 15 years old and under, as one participant said: “...a child who is 15 years old should be closely monitored; that is, he/she should be made to understand that he/she should not do 'that act' [...], and for those who are older than 15 years should be warned against engaging in irresponsible and unprotected sex" (17-year-old, female adolescent).

Communication about the use of condoms: The majority of participants did not support communication about the use of condoms because they believe that once adolescents are informed about how to use a condom properly, they would be tempted to try it out. Others believed that condoms are not effective in protecting oneself against diseases because they believe that condoms have pores and may have side-effects to the users, as one participant said:

I really don't know what we should do with today's young ones, (group laughed), because condoms are available and sexual activities by the young ones have increased to $90 \%$; but these condoms have many side effects. They reduce a man's sexual power, tiring the nerves, and even for ladies I think condoms are hurting them (...) and also condoms have pores, so they cannot protect the user against HIV... (19-yearold, male adolescent).

The use of condoms has also been considered by some as an act which is against their tradition and religious 
beliefs, as divulged by one participant: “...if you teach to use condoms it is like you are encouraging them to practice 'that act', while our mission is to prevent 'that act' [...] even in our religion, it is not allowed, our Lord tells us to stay clear of this act" (17- year-old, male adolescent).

Those who supported communication about the use of condoms, between caretakers and adolescents, were of the opinion that this kind of communication would help to prevent the incorrect use of condoms. Adolescents will therefore be able to protect themselves from sexually transmitted diseases, now that they seem to engage in many sexual and health related risky behaviours. However, many emphasised that communication about the use of condoms should only be to those who are sexually active, and who are 18 years old and above, and this communication should be on the same sex basis; that is, a female caretaker should communicate with a female adolescent, and a male caretaker to a male adolescent. One male participant elaborates: “...it is good if they [adolescents] are sensitised, but a female caretaker should talk to a female adolescent and vice versa. These adolescents should not be engaged when they are too young; it is better to wait until they reach the age when they are sexually active" (16-year-old, male adolescent).

Communication about the use of contraceptives: Many participants responded positively about communicating with adolescents about the use of contraceptives although the majority emphasised that it should be communicated to those who are sexually active and to those who are about to get married, or those who are at least 18 years old. They believe that if they start using these contraceptives at a young age, the effects might be serious as they grow older. One participant who was justifying this point: “...I think once a parent notices that her/his daughter has started behaving differently... like engaging in risky behaviour, he/she should talk to her about the use of contraceptives, to avoid unwanted pregnancies" (19-year-old, school female adolescent).

Some did not support the idea that parents should communicate about the use of contraceptives because they believe that if adolescents are taught about the use of such contraceptives, they would become promiscuous as they well know that they won't get pregnant, although there is still the risk of contracting sexually transmitted diseases. This was explained by one participant who said: "I think we should not look at pregnancy alone, rather we should also consider sexually transmitted diseases; if you teach how to use contraceptives to prevent unwanted pregnancy, what about diseases?" (18-year-old, school male adolescent).

Barriers affecting communication on sexuality: It was important to find out what barriers affect communication about sexuality between caretakers and adolescents. This study found out that there are barriers that hinder caretakers to initiate communication about sexuality to their adolescents; these include "fear". Many parents "fear" their children, because they shout back at their parents, and some ignore them once they start talking. Some parents think that their adolescents know more about sexuality than themselves because of development of telecommunication and globalisation, and some parents believe that their children are too young for this kind of conversation. There are others who believe that if they talk to their adolescents about sexuality it would be like they are encouraging them to engage in sexual activities; as one said: "Some parents fear that if they talk to their adolescents about reproductive health they will be like encouraging them to practice 'that act' (meaning sex), because if you tell your daughter that if you do this and that you won't get pregnant, the child may become miscellaneous, because she knows for certain that she won't get pregnant” (18-year-old, female adolescent).

It also became apparent that some parents have limited knowledge of sexuality and reproductive health, lack opportune time as they spend a lot of time earning a living. Others also feel that communicating about sexuality is against their custom, and that communicating about sexuality with adolescents would be disrespectful. There is again the feeling of shame and embarrassment; as one participant elaborated: “...the problem of limited knowledge among parents prevents them from communicating with their adolescents" (18-year-old, school male adolescent).

On the other hand, barriers that hinder adolescents from initiating communication about sexuality with their caretakers include "fear" of parents, especially if they already have had a reproductive health problem, or they are sexually active and/or involved with bad groups, as one participant said: “...sometimes you wonder in your mind if you go and ask your mother about sexuality and reproductive health information, what she would think of you. You therefore, at that moment, develop fear; you become so anxious, feeling she may think bad about you, therefore you decide (she laughed)... you decide not ask her" (19-year-old female adolescent).

Others said that their parents are unapproachable; they are not close enough with their adolescents, to allow them develop the necessary confidence to ask questions. One participant intimated thus: "I can say that parents or caretakers contribute in one way or another in spoiling the children, because some parents are unapproachable, they are always angry, you cannot even talk to them..." (17-year-old, male adolescent). 


\section{Discussion}

This study examined adolescents' views, needs and attitude to receiving information on sexuality from their parents. The issues which emerged from the focus group discussions were: the importance of communication on sexuality, the preferred person to communicate about sexuality, the appropriate age to start communication on sexuality, the type of information to be communicated, and barriers that affect such communication. These issues are discussed in this section.

\subsection{The Importance of Communication about Sexuality}

The findings show that the participant found it important for caretakers to communicate with their adolescents about sexuality, in order to avoid sexually and related health risks. Communication about sexuality is believed to make the adolescent confident and thus capable of making informed decisions about his/her sexual health. Moreover, communication about sexuality will help the adolescent to appreciate the risks around him/her including the effect of peer pressure together with the consequences of own risky behaviours, and consequently know how to protect self from those effects. On top of that, this communication will allow the adolescent' mind to mature, helping them to plan for their future. This finding is consistent with the findings of Rosenthal and Feldman (1999), which also showed that adolescents have positive perceptions on the importance of caretakeradolescent sexuality communication, but this is only true for some topics like sexuality safety which include safe sex, contraception, HIV and STIs, and to a lesser extent the development and societal concern which include menstruation, pregnancy and physical development [21].

This positive response of participants on the importance of communication about sexuality can be explained by the excessive existence of sexual and related health risky behaviours together with the evident effects like teenage pregnancy among adolescents. It was noted that globalisation has exposed many young people to risky reproductive health problems due to easy access to porn videos through internet, the use of mobile phones which allows for easy communication, material, money and luxury desires, low economic status, peer pressure and imitating foreign life styles. All these put young people at risk of early sexual debut, as it was found in this study. Adolescents initiate sexual activities even before they reach puberty, as early as when they are only 7 to 15 years, and they usually practice this with older partners. Kaufman and Stavrouv (2004) and Longfield (2004) warn that these relationships involving young women and older men are very risky [30] [31]. This supports the recommendations in other studies about initiating discussion about sexuality with children who are much younger, even before they are sexually active [32] [33].

\subsection{The Preferred Person to Communicate on Sexuality Matters}

Since communication about sexuality is perceived as taboo and usually embedded with feelings of embarrassment and shame [5], this study has found that adolescent participants prefer to communicate this information with someone whom they are comfortable with, someone who knows them and can understand them well, one who has knowledge of sexuality and skills to communicate. The majority chose parents as their preferred person to communicate with about sexuality because they believe that their parents/caretakers know them and understand them well since they live under one roof and spend much time together. This finding concurs with the finding of Guilamo-Ramos et al. (2012) and Namisi et al. (2009) which also showed that adolescents chose parents as the preferred source of information about sexual topics [26] [34]. This implies that caretakers are significant individuals to be included in any intervention aiming at reducing young people's sexual risky behaviours. This finding supports the evidence in developing countries showing the need to involve parents in the strategies of improving young people's health and development [35].

Equally important, it was necessary to explore whether or not the sex of the caretaker matters when communicating to adolescents about sexually related matters. While some believe that communication on sexuality should not be gender-sensitive for all topics, except for more sensitive topics like menstruation, bed-wetting, secondary sexual characteristics, the use of condoms and contraceptives, others believe that information on sexuality should be handled by a caretaker of the same sex as the adolescents. This finding is consistent with the finding of Tesso et al. (2012) which also showed that young people preferred discussion on sexuality and reproductive health matters with the same sex [27]. This supports the recommendation from the study of Wamoyi et al. (2010) who suggested that there is a need for developing programmes to teach both parents and young people to communicate explicitly and clearly [22]. 


\subsection{Appropriate Age to Start Communication on Sexuality}

The age that participants thought was appropriate to initiate communication about sexuality was important to be explored. This study found that communication about sexuality should be initiated once the child reaches puberty; that is between 9 to 15 years for girls and 15 years for boys, because they said this is the period when adolescents start to develop behavioural change and may engage in sexual risky behaviour due to body physiological changes that come with age. This perception is different from what is found in the study of GuilamoRamos et al. (2012) which showed that most boys and girls felt it was appropriate to discuss sexual matters with their parents between the age of 18 and 21 years, or after marriage, because of the feelings that older people will not feel comfortable to speak about this topic at such young age [26]. However in the same study few adolescents thought sex was an appropriate topic for young adolescents who lacked the maturity to process such information [26]. The latter is consistent with the findings of this study which shows that some adolescents concurred with the fact that the youth have to be advised about sexuality even before puberty, as alluded to earlier- "strike the iron while still hot".

\subsection{Type of Information to Be Communicated}

Adolescents are not passive recipients of information or instructions from their parents, therefore it was important to find out whether the young person feels it is appropriate or important that his/her parents deals with a given topic, because adolescents differentiate areas where parents may offer information or advice and areas where parental inputs is seen as unwanted and inappropriate [21]. Among the topics of sexuality that adolescents think should be communicated to them, information about condom use was the most unsupported topic. The majority believe that if you teach adolescents about how to use a condom is like you are encouraging them to engage in sex, an act some of them consider to be culturally and religiously unacceptable. In contrast, information about contraceptive use seem to be more interesting to the majority of participants, although they emphasised that this information should be given to those who are sexually active, or who are about to get married. However, the study of Rosenthal and Feldman (1999) showed that there was pervasive agreement among adolescents that parents should only communicate about sexual safety which include safe sex, contraceptive use, STIs and HIV, and to a lesser extent development and societal concerns which include biological aspects, pregnancy and abortion [21].

\subsection{Barriers That Affect Communication about Sexuality}

Findings from this study show that participants perceived that the barriers that affect communication about sexuality between caretaker and adolescent arise from both parents and their children. Some parents believe that their children are too young for such kind of conversation, and others believe that if they talk to their adolescents about sexuality it will be like tempting them to engage in sexual activities. Some caretakers "fear" their children, some parents think that their adolescents know more about sexuality than themselves. This finding is similar to the finding from a study by Muyinda et al. (2003) done in Uganda which showed that traditional sex educators (known as Senga) felt that their role was no longer valuable since young ones knew more about sexuality than they did [36]. But also lack of communication is attributed to limited knowledge and skills for caretakers to communicate effectively with their children, lack of opportune time by parents, lack of confidence on the part of the caretakers, shyness, etc. This finding is similar to the findings of Guilamo-Ramos et al. (2012) in a study done in India which found that adolescents identified a number of barriers of communicating about sexual matters, including embarrassment in discussing sexual topics, concerns that discussions about sex were not age appropriate, and lack of information [26]. On the part of the adolescents, they were of the opinion that parents were not sufficiently friendly, and the fact that they were not sure about what their parents would think of them if they kept on asking questions about sexuality. This finding is also consistent with the study of Guilamo-Ramos et al. (2012) which showed that both boys and girls were afraid of asking their parents questions about sex, as they did not want their parents to discover that they were already sexually active [26].

\subsection{IMB-Model in Relation to This Study}

1) Information construct

Contents and importance of sexuality and reproductive health information: The findings indicated that par- 
ticipants have knowledge about the topics of sexuality and reproductive health to be communicated. However, the majority mentioned topics based on the preventive aspects of sexuality, ranging from wearing respectable cloth, avoiding bad groups, avoiding any sexual temptations and abstaining from sexual activities. Some mentioned topics related to associated risk aspect of sexuality like HIV and STDs, pregnancy and abortion. The topics that were least mentioned were about biological aspects of sexuality, and those that were not mentioned at all were sexual desire, and how to deal with unwanted sexual pressure. Moreover, there was strong disapproval about communicating information on condom use, claiming that religiously condom use is not acceptable, and it was associated with false belief that teaching adolescent about condom use will cause promiscuity, and condoms are not effective in preventing sexual transmitted diseases. On the other hand, information about contraceptives was mostly supported; it was taken as a family planning method which is acceptable, but it was also emphasised that such information should be given to those adolescents who are sexual active, married or about to get married. Most participants showed positive response on the importance of information on sexuality, adolescent sexual health, and the majority mentioned that such information would allow adolescents to make informed decision about their sexual behaviour. The knowledge gap that has been identified in this study needs to be considered in any intervention aiming at improving adolescents' sexual health especially in this area.

\section{2) Motivation construct}

Perceived risk: Many participants acknowledged the risk that adolescents are putting themselves at, due to the increasing rate of mobile phone use, internet, and the issue of taking advantage of globalisation as whole, peer pressure, easy access of drugs, alcohol and cigarettes. However, almost all participants associated the risk to the "third person" while excluding themselves. This implies that there is a need to create awareness to adolescents so that they acknowledge that they are at the same risk as other adolescents in their surroundings.

Social norms: This study found that there are some sorts of restricted social norms to communication about sexuality, especially when such communication involves communication about the use of condoms or communication with the opposite sex. Participants admitted that their parents won't talk to them about sensitive issues like condom use, worrying about what other people would think of them, or sometimes feeling people would accuse them of following a foreign life style. This issue also needs to be addressed.

Attitude: Prior to this research it was assumed that adolescents are unwilling to discuss sex-related topics with their parents. However, our findings suggest that most participants feel it is a good thing to discuss sexuality with parents, acknowledging its impact in the sexual health of adolescents. This suggests that information on sexuality is essential.

\section{3) Behavioural skills}

Perceived self-efficacy: The majority acknowledged that they would not go to their parents and ask about information on sexuality because this might suggest that they are already sexually active. They also hesitate to ask their parents because they think their parents are not approachable. This finding suggests that if communication barriers were overcame, adolescents might in fact be open to such discussions.

\section{Limitation}

This study like any others in the field of social sciences has its limitation that is worth noting when interpreting the findings. Due to the sensitivity of sexuality issues that were assessed, social desirability, privacy concerns and potential embarrassment may have lead to concealment of their perceptions and therefore under or over-reporting. However, efforts were taken to encourage open and free discussion, and confidentiality were highly ensured.

\section{Conclusion}

Despite existing barriers, adolescents are concerned about their sexual health and well-being. Findings from this research suggest that adolescents are interested in talking about sexual topics with their caretakers. These findings are encouraging and suggest that intervention strategies that help to alleviate communication barriers can facilitate caretaker-adolescent discussions about sexuality and reproductive health. This information is necessary if we are to support the motivation of adolescents to effectively communicate with their parents about how to change their risk behaviour. The findings also have important implications for researchers interested in developing familybased interventions to reduce risky behaviours to adolescents in Unguja Zanzibar. 


\section{Acknowledgements}

We are very grateful to Sida Capacity Strengthening Programme, through Muhimbili University of Health and Allied Sciences, for funding this study. Sincere thanks to all study participants who shared their perceptions about caretaker-adolescent communication about sexuality with us.

\section{References}

[1] Kirby, D. (2007) Emerging Answers: Research Findings on Programs to Reduce Teen Pregnancy and Sexually Transmitted Diseases. The National Campaign to Prevent Teen and Unplanned Pregnancy, Washington DC.

[2] Lehr, S.T., Dilorio, C., Dudley, W.N. and Lipana, J.A. (2000) The Relationship between Patient-Adolescent Communication and Safer Sex Behaviours in College Students. Journal of Family Nursing, 6, 180-196. http://dx.doi.org/10.1177/107484070000600206

[3] Markham, C.M., Lormand, D., Gloppen, K.M., Peskin, M.F., Flores, B., Low, B. and House, L.D. (2010) Connectedness as a Predictor of Sexual and Reproductive Health Outcomes for Youth. Journal of Adolescent Health, 46, S23S41. http://dx.doi.org/10.1016/j.jadohealth.2009.11.214

[4] DiClemente, R.J., Wingood, G.M., Crosby, R., Cobb, B.K., Harrington, K. and Davies, S.L. (2001) Parent-Adolescent Communication and Sexual Risk Behaviours among African American Adolescent Females. Journal of Pediatrics, 139, 407-412. http://dx.doi.org/10.1067/mpd.2001.117075

[5] Taffa, N., Bjune, G., Sundby, J., Gaustad, P. and Alestrom, A. (2002) Prevalence of Gonococcal and Chlamydial Infections and Sexual Risk Behaviour among Youth in Addis Ababa, Ethiopia. Sexually Transmitted Diseases, 29, 828833. http://dx.doi.org/10.1097/00007435-200212000-00015

[6] Kirby, D., Obasi, A. and Laris, B.A. (2006) The Effectiveness of Sex Education and HIV Education Interventions in Schools in Developing Countries. World Health Organization Technical Report Series, 938, 103-150.

[7] Hubbacher, D., Mavranezouli, I. and McGinn, E. (2008) Unintended Pregnancy in Sub Saharan Africa: Magnitude of the Problem and Potential Role of Contraceptives Implants to Alleviate It. Contraception, 78, 73-78. http://dx.doi.org/10.1016/j.contraception.2008.03.002

[8] Urassa, W., Moshiro, C., Chalamila, G., Mhalu, F. and Sandstorm, E. (2008) Risky Sexual Practices among Youth Attending a Sexually Transmitted Infection Clinic in Dar es Salaam, Tanzania. BMC Infectious Diseases, 8, 159. http://dx.doi.org/10.1186/1471-2334-8-159

[9] National AIDS Control Program (NACP) (2002) Report No. 16: Ministry of Health, Dar es Salaam, Tanzania.

[10] UNAIDS/WHO (2010) Epidemiological Fact Sheet on HIV and AIDS. UNAIDS/WHO, Geneva.

[11] United Nation (UN) (2011) HIV and AIDS: Challenges and Opportunities. United Nation, Geneva.

[12] World Health Organization (WHO) (1998) Unsafe Abortion: Global and Regional Estimates of Incidence of and Mortality Due to Unsafe Abortion with a Listing of Available Country Data. World Health Organization, Geneva.

[13] United Nations (UN) (1990) Patterns of First Marriage: Timing and Prevalence. United Nations, Department of International Economic and Social Affairs, New York, ST/ESA/SER.R/111, 7-18.

[14] Bledsoe, C.H. and Cohen, B. (1993) Social Dynamics of Adolescent Fertility in Sub-Saharan Africa. Population Dynamics of Sub-Saharan Africa, National Academy Press, Washington DC, 45-56.

[15] Mensch, B.S., Grant, M.J. and Blanc, A.K. (2006) The Changing Context of Sexual Initiation in Sub-Saharan Africa. Population and Development Review, 32, 699-727. http://dx.doi.org/10.1111/j.1728-4457.2006.00147.x

[16] Office of Chief Government Statician (2010) Tanzania Demographic Health Survey. Office of Chief Government Statician, Zanzibar.

[17] Taffa, N., Klepp, K., Austveg, B. and Sundby, J. (1999) Adolescent Sexual and Reproductive Health; Review of Current Facts, Programmes and Progress since ICPD. Norwegian Ministry of Foreign Affairs and Norwegian Board of Health.

[18] Biddlecom, A.E., Hessburg, L., Singh, S., Bankole, A. and Darabi, L. (2007) Protecting the Next Generation in SubSaharan Africa: Learning from Adolescents to Prevent HIV and Unintended Pregnancy. Guttmacher Institute, New York.

[19] Munguti, K., Grosskurth, H., Newell, J., Senkoro, K., Mosha, F., Todd, J., et al. (1997) Patterns of Sexual Behaviour in a Rural Population in North-Western Tanzania. Social Science \& Medicine, 44, 1553-1561. http://dx.doi.org/10.1016/S0277-9536(97)00014-2

[20] Bankole, A., Ahmed, F., Neema, S., Ouedrago, C. and Konyani, S. (2007) Knowledge of Correct Condom Use and Consistency of Use among Adolescents in Four Countries in Sub-Saharan Africa. African Journal of Reproductive Health, 
11, 197-220. http://dx.doi.org/10.2307/25549740

[21] Rosenthal, D.A. and Feldman, S.S. (1999) The Importance of Importance: Adolescents’ Perceptions of Parental Communication about Sexuality. Journal of Adolescence, 22, 835-851. http://dx.doi.org/10.1006/jado.1999.0279

[22] Wamoyi, J., Fenwick, A., Urassa, M., Zaba, B. and Stones, W. (2010) Parent-Child Communication about Sexual and Reproductive Health in Rural Tanzania: Implications for Young People's Sexual Health Interventions. Reproductive Health, 7, 6. http://dx.doi.org/10.1186/1742-4755-7-6

[23] Bastien, S., Leshabari, M.T. and Klepp, K.I. (2009) Exposure to Information and Communication about HIV/AIDS and Perceived Credibility of Information Sources among Young People in Northern Tanzania. African Journal of AIDS Research, 8, 213-222. http://dx.doi.org/10.2989/AJAR.2009.8.2.9.861

[24] Mellanby, A.R., Newcombe, R.G., Rees, J. and Tripp, J.H. (2001) A Comparative Study of Peer-Led and Adult-Led School Sex Education. Health Education Research, 16, 481-492. http://dx.doi.org/10.1093/her/16.4.481

[25] Jaccard, J., Dittus, P.J. and Gordon, V.V. (2000) Parent-Teen Communication about Premarital Sex: Factors Associated with the Extent of Communication. Journal of Adolescent Research, 15, 187-208. http://dx.doi.org/10.1177/0743558400152001

[26] Guilamo-Ramos, V., Soletti, A.B., Burnette, D., Sharma, S., Leavitt, S. and McCarthy, K. (2012) Parent-Adolescent Communication about Sex in Rural India: US-India Collaboration to Prevent Adolescent HIV. Qualitative Health Research, 22, 788-800. http://dx.doi.org/10.1177/1049732311431943

[27] Tesso, D.W., Fantahun, M.A. and Enquselassie, F. (2012) Parent-Young People Communication about Sexual and Reproductive Health in E/Wollega Zone, West Ethiopia: Implications for Interventions. Reproductive Health, 9, 13. http://dx.doi.org/10.1186/1742-4755-9-13

[28] Fisher, J.D. and Fisher, W.A. (1992) Changing AIDS-Risk Behaviour. Psychological Bulletin, 111, 455-474. http://dx.doi.org/10.1037/0033-2909.111.3.455

[29] Zarani, F., Besharat, M., Sarami, G. and Sadeghian, S. (2012) An Information-Motivation-Behavioural Skills (IMB) Model-Based Intervention for CABG Patients. International Journal of Behavioral Medicine, 19, 543-549. http://dx.doi.org/10.1007/s12529-011-9193-2

[30] Kaufman, C.E. and Stavrouv, S.E. (2004) "Bus Fare Please”: The Economics of Sex and Gifts among Young People in Urban South Africa. Culture, Health \& Sexuality, 6, 377-391. http://dx.doi.org/10.1080/13691050410001680492

[31] Longfield, K. (2004) Rich Fools, Spare Tyres and Boyfriends: Partner Categories, Relationship Dynamics and Ivorian Women's Risk for STIs and HIV. Culture, Health \& Sexuality, 6, 483-500. http://dx.doi.org/10.1080/13691050410001701920

[32] Obasi, A.I., Cleophas, B., Ross, D.A., Chima, K.L., Mmassy, G., Gavyole, A., Plummer, M.L., Makokha, M., Mujaya, B., Todd, J., et al. (2006) Rationale and Design of the MEMA kwa Vijana Adolescent Sexual and Reproductive Health Intervention in Mwanza Region, Tanzania. AIDS Care, 18, 311-322. http://dx.doi.org/10.1080/09540120500161983

[33] Cowan, F.M., Pascoe, S.J., Langhaug, L.F., Diwaro, J., Chidya, S., Jaffar, S., Mbivzo, M., Stephenson, J.M., Johnson, A.M., Power, R.M., et al. (2008) The Regai Dzive Shiri Project: A Cluster Randomized Controlled Trial to Determine the Effectiveness of a Multi-Component Community-Based HIV Prevention Intervention for Rural Youth in Zimbabwe-Study Design and Baseline Results. Tropical Medicine \& International Health, 13, 1235-1244. http://dx.doi.org/10.1111/j.1365-3156.2008.02137.x

[34] Namisi, F.S., Flisher, A.J., Overland, S., Bastien, S., Onya, H., Kaaya, S. and Aarø, L.E. (2009) Socio-Demographic Variations in Communication on Sexuality and HIV/AIDS with Parents, Family Members and Teachers among in School-Adolescents: A Multi-Site Study in Tanzania and South Africa. Scandinavian Journal of Public Health, 37, 65-74. http://dx.doi.org/10.1177/1403494808086986

[35] World Health Organization (WHO) (2007) Helping Parents in Developing Countries Improve Adolescent’s Health. World Health Organization, Geneva.

[36] Muyinda, H., Nakuya, J., Pool, R. and Whitworth, J. (2003) Harnessing the Senga Institution of Adolescents Sex Education for the Control of HIV and STDs in Rural Uganda. AIDS Care, 15, 159-167. http://dx.doi.org/10.1080/0954012031000068308 
Scientific Research Publishing (SCIRP) is one of the largest Open Access journal publishers. It is currently publishing more than 200 open access, online, peer-reviewed journals covering a wide range of academic disciplines. SCIRP serves the worldwide academic communities and contributes to the progress and application of science with its publication.

Other selected journals from SCIRP are listed as below. Submit your manuscript to us via either submit@scirp.org or Online Submission Portal.
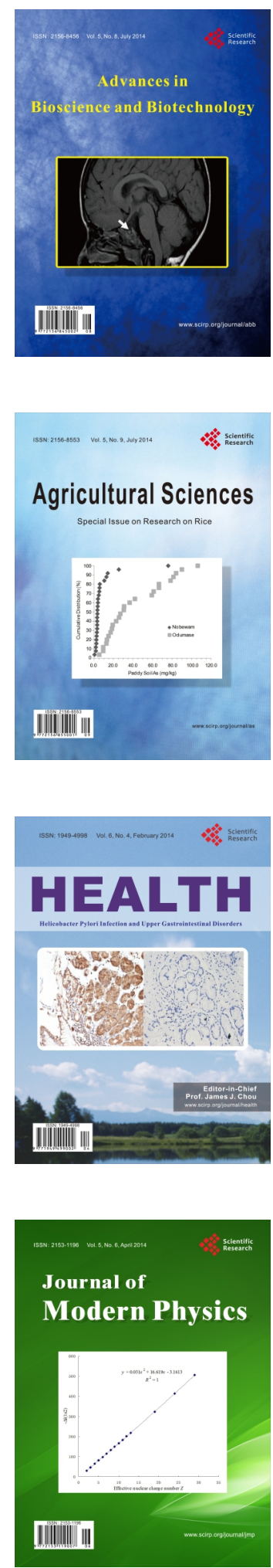
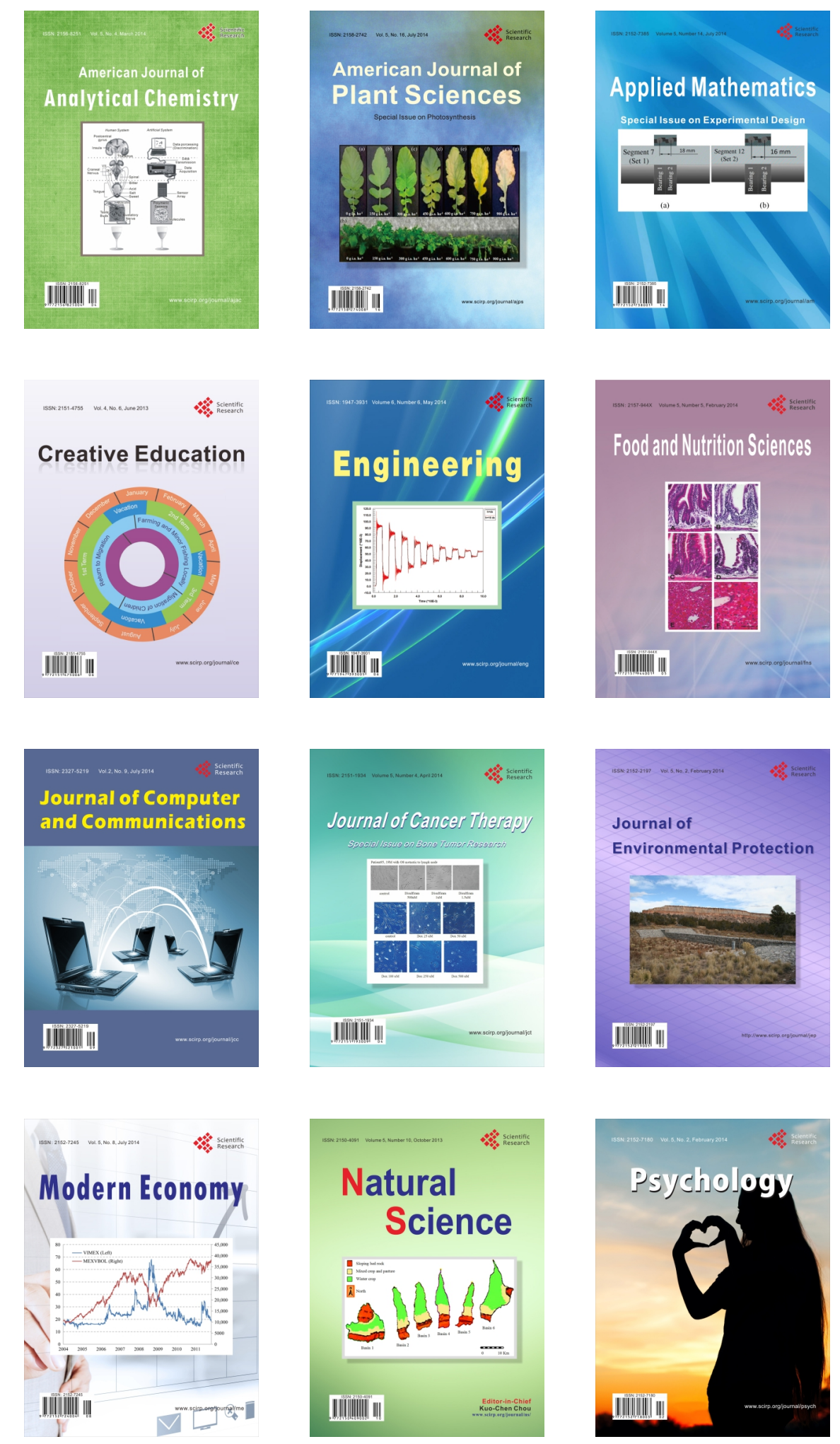